\title{
The effect of hydrofluoric acid and resin cement formulation on the bond strength to lithium disilicate ceramic
}

\section{Daniel SUNDFELD(a) \\ Alan Rodrigo Muniz PALIALOL ${ }^{(b)}$ Ana Paula Piovesan FUGOLIN ${ }^{(c)}$ Gláucia Maria Bovi AMBROSANO(d) Lourenço CORRER-SOBRINHO(b) Luis Roberto Marcondes MARTINS(b) Carmem Silvia PFEIFER(c)}

(a) Ingá University Center - UNINGÁ, School of Dentistry, Department of Restorative Dentistry and Prosthodontics, Maringá, PR, Brazil.

(b) Universidade Estadual de Campinas - Unicamp, Piracicaba Dental School, Department of Restorative Dentistry, Piracicaba, SP, Brazil.

(c) Oregon Health \& Science University OHSU, Department of Restorative Dentistry, Division of Biomaterials and Biomechanics, Portland, Oregon, United States.

(d) Universidade Estadual de Campinas - Unicamp, Piracicaba Dental School, Department of Social Dentistry, Piracicaba, SP, Brazil.

Declaration of Interests: The authors certify that they have no commercial or associative interest that represents a conflict of interest in connection with the manuscript.

Corresponding Author:

Daniel Sundfeld

E-mail: sundfeldneto@gmail.com

htrps://doi.org/10.1590/1807-3107bor-2018.vol32.0043

Submitted: Dec 02, 2017

Accepted for publication: Mar 27, 2018

Last revision: Apr 11, 2018
Abstract: To investigate how the hydrofluoric acid (HF) concentrations applied to a lithium disilicate glass-ceramic (EMX) affects the surface morphology and microtensile bond strength ( $\mu \mathrm{TBS}$ ) of ceramics to dentin, using light-cured resin cements with or without UDMA. Sixty-three EMX square ceramic blocks were etched for 20 seconds using different HF concentrations (1\%, 5\% and 10\%) and luted to dentin using two types of resin cement combinations: BisGMA/TEGDMA and BisGMA/TEGDMA/UDMA ( $\mathrm{n}=10)$. Each bonded EMX-dentin block was sectioned to obtain $1 \mathrm{~mm}^{2}$ sticks for $\mu \mathrm{TBS}$ evaluation. Half of the sticks were tested after 24 hours and the other half was assessed after 6 months of water storage. Data were statistically assessed using split-plot three-way ANOVA and multiple comparisons were performed using the Tukey's post hoc test $(\alpha=0.05)$. One EMX sample from each HF concentration was analyzed using field-emission scanning electron microscope (FE-SEM) to characterize the etching pattern. According to the FE-SEM images, increasing the concentration of HF from 1 to 5 and then to $10 \%$ led to increased removal of glassy matrix and greater exposure of lithium disilicate crystals. The 10\% HF concentration yielded higher $\mu$ TBS when compared to $1 \%$ for BisGMA/TEGDMA formulation ( $p<0.05$ ); whereas HF $1 \%$ and $5 \%$ showed similar $\mu$ TBS values when compared to $10 \% \mathrm{HF}$ for BisGMA/TEGDMA/UDMA resin matrix ( $p>0.05$ ) at both storage times. Water aging decreased the $\mu$ TBS values ( $p<0.05$ ), except when $10 \%$ HF was associated with BisGMA/ TEGDMA resin cement. Resin cement formulation and hydrofluoric acid concentrations can interfere with the immediate and long-term glass-ceramic bond strength to dentin.

Keywords: Hydrofluoric Acid; Resin Cements; Dentin; Electron Microscope Tomography.

\section{Introduction}

Due to their optimal mechanical/optical properties, chemical durability and survival rates, ${ }^{1,2}$ dental glass-ceramics are one of the most adopted indirect restorative materials for reestablishing function, shape and esthetics of affected dentition. The lithium disilicate glass-ceramic is noteworthy among glass-ceramics due to its outstanding natural look-like, ${ }^{3}$ translucency and high mechanical strength., ${ }^{1,4}$ 
As lithium disilicate glass-ceramic is suitable to be adhesively bonded to dental tissues, the bond between glass-ceramics and resin cements is one of the key factors for long-term clinical success. ${ }^{5}$ Although hydrofluoric acid (HF) etching followed by silane application is recognized as the most widely accepted procedure before luting glass-ceramic with resin cements, $3,5,6,7,8$ the ideal etching protocol is still not clear. ${ }^{4}$ The manufacturer of IPS e.max Press (EMX) (Ivoclar Vivadent, Schaan, Liechtenstein), a pressable lithium disilicate glass-ceramic, recommends etching EMX with $4.8 \% \mathrm{HF}$ for 20 seconds. On the other hand, in vitro studies and clinical case reports have demonstrated concentrations of up to $10 \%$. $3,6,7,8$

The hazardous nature of $\mathrm{HF}^{9}$ has led researchers ${ }^{10,11}$ to assess the effects of HF concentrations lower than $5 \%$ applied at room temperature on EMX, which showed underwhelming bond strength results. Most in vitro studies ${ }^{6,7,10,11,12,13,14,15}$ have focused on the bond strength of lithium disilicate to the ceramic-resin cement or resin composite interfaces.

Resin cements are responsible for mechanically/ chemically bonding the glass ceramics to tooth. Those materials must have high mechanical properties, adequate bond strength to tooth tissues and structures, high resistance to dissolution and satisfactory bonding to non-retentive tooth preparations to withstand the constant incidence of tensile/oblique/compressive masticatory loads found in the oral environment. ${ }^{16,17}$ Previous reports $8,18,19,20$ assessed the bond strength of lithium disilicate ceramics etched with only one specific HF concentration and then luted to dentin using different chemical-physical setting modalities available for commercial resin cements. As the main components of resin matrix are methacrylate-based materials, such as Bis-GMA (bis-phenol A diglycidyl dimethacrylate), TEGDMA (tri-ethylene glycol dimethacrylate) and UDMA (urethane dimethacrylate), ${ }^{21,22}$ their role on the bonding between EMX etched with different HF concentrations to dentin has not been investigated so far. As not all commercially available resin cements present UDMA (such as RelyX Veneer, 3M ESPE, St. Paul, MN, USA) and considering the distinct chemical and physical properties of UDMA compared to BisGMA and TEGDMA ${ }^{23,24,25}$ it becomes necessary to investigate the role of UDMA on the bonding characteristics to EMX as well.
Therefore, the aim of the present in vitro study is to assess the effect of three HF concentrations $(1 \%, 5 \%$ and $10 \%$ ) on the etching morphology and microtensile bond strength ( $\mu \mathrm{TBS})$ of lithium disilicate glass-ceramic luted to dentin using light curing resin cements with and without UDMA at immediately after preparation and after 6-month of water storage. The null hypotheses tested were: 1) Different $\mathrm{HF}$ concentrations would not affect the $\mu \mathrm{TBS}$; 2) Resin cement matrices would not influence the $\mu \mathrm{TBS}$; and 3) Water storage would not decrease $\mu \mathrm{TBS}$.

\section{Methodology}

\section{Ceramic blocks}

Sixty-three square ceramic blocks $(8 \mathrm{~mm} \times 8 \mathrm{~mm}$ x $3 \mathrm{~mm}$ thick) were fabricated from IPS e.max Press ingots (Ivoclar Vivadent, Schaan, Liechtenstein, shade LTA2), according to the manufacturer's instructions and as described in a previous study. ${ }^{11}$ After divestment, the EMX blocks were wet-polished with 1000-, 2500and 4000-grit silicone carbide abrasive papers (Buehler, Lake Buff, USA) to obtain a flat surface.

\section{Hydrofluoric acid etching of IPS e.max Press}

A person that was not involved in the study and blinded to the groups randomly divided the EMX blocks into 3 groups according to the hydrofluoric acid (HF) concentrations: 1\%, 5\% and 10\% (Fórmula \& Ação, São Paulo, Brazil) ( $\mathrm{n}=21)$. The etching time was fixed at 20 seconds and, following etching, the HF was removed using air/water spray for 1 minute and the specimens were ultrasonically cleaned with deionized water for 20 minutes and air dried.

\section{Field-emission scanning electron microscopy (FE-SEM) evaluation}

One random etched EMX specimen was selected (in the same manner adopted for the groups distribution) from each group to characterize the resultant etching pattern. The etched EMX specimens were mounted on coded brass stubs, sputter coated with gold-palladium for 60 seconds at $45 \mathrm{~mA}$ (Denton Vacuum Desk II, Moorestown, USA) and submitted to FE-SEManalysis (FEI Quanta200Environmental Scanning Electron Microscope, Hillsboro, USA) at $20 \mathrm{kV}$. Images were obtained with a $3,038 \times$ magnification and $10 \mu \mathrm{m}$ scale bars. 


\section{Resin cement formulation}

After HF etching, specimens from each group were randomly distributed into 2 subgroups according to the resin cement formulation $(n=10)$. The chemical components of the resin matrix were mixed using the following materials: bis-phenol A dyglycidyl dimethacrylate (Bis-GMA; Esstech, Essington, USA); tri-ethylene glycol dimethacrylate (TEGDMA; Esstech, Essington, USA); and urethane dimethacrylate (UDMA; Esstech, Essington, USA). The type 1 resin cement matrix was formulated using Bis-GMA and TEGDMA in a 1:1 mass ratio. The type 2 resin cement had the addition of UDMA, with the final resin matrix composition presenting Big-GMA, TEGDMA and UDMA in a 5:2:3 mass ratio. All the resin cements components are disclosed in Table 1.

Photoinitiators were added to the resin matrix as follows: $0.8 \mathrm{wt} \%$ of a tertiary amine (EDMAB, ethyl 4-dimethylaminobenzoate; Avocado, Heysham, England), $0.2 \mathrm{wt} \%$ of dl-camphoroquinone (CQ, Polysciences Inc., Warrington, USA) and $0.1 \mathrm{wt} \%$ inhibitor (BHT, 2,6-di-tert-butyl-4-methylphenol; SigmaAldrich, St. Louis, USA). Barium borosilicate glass filler (Esstech, Essington, PA, USA) was mixed into the resin matrix using a mechanical mixer (DAC 150 Speed mixer, Flacktek, Landrum, USA) for 5 min at 2,500 rpm at a 1:1 mass ratio with the resin matrix. All the procedures were performed under yellow lights in order to prevent photoinitiator (CQ) degradation.

\section{Bonding procedures}

\section{Dentin surface treatment}

Sixty-five freshly extracted human third molars were obtained from the Oregon Health \& Science University and stored in $0.5 \%$ chloramine at $4^{\circ} \mathrm{C}$ until use. The coronal third was removed to expose the mid-dentin portion, wet-polished with $-600 \mathrm{SiC}$ abrasive papers for 60 seconds to produce a smear layer, and rinsed. Dentin was further etched with 32\% phosphoric acid (Scotchbond Universal Etchant, 3MESPE, St. Paul, USA) for 15 seconds and air-water sprayed for 30 seconds to remove the phosphoric acid. Later, excess of water was removed using a dry cotton-pellet to leave a moist dentin.

The primer of a three-step etch-and-rinse adhesive system (Scotchbond MultiPurpose, 3MESPE, St. Paul, USA) was applied to the dentin surface and air-dried for 15 seconds. A thin layer of the bonding agent (Scotchbond MP, 3MESPE) was also applied to the dentin and light cured for 10 seconds using an LED curing device (Valo, Ultradent Inc., South Jordan, USA), with an irradiance of $1,000 \mathrm{~mW} / \mathrm{cm}^{2}$.

\section{IPS e.max press surface treatment}

After HF etching, a silane coupling agent (RelyX Ceramic Primer, 3MESPE, St. Paul, USA) was applied onto all specimen surfaces and allowed to air dry for 1 minute, followed by air-heat drying $\left(60^{\circ} \mathrm{C} \pm 5\right)$ for 1 minute. A thin layer of a bonding agent (Scotchbond MP, 3MESPE) was applied to the ceramic surface for 10 seconds.

\section{Luting the IPS e.max press to dentin}

The resin cement was poured onto the dentin surface and the etched EMX surface was pressed against it under a vertical static load of 1 kilogram for 120 seconds. Light-activation was performed for 40 seconds at each of the EMX/dentin sides (four activations) and a final 60 seconds of light curing through the bulk of the ceramic. All bonded specimens were stored in deionized water for 24 hours at $37^{\circ} \mathrm{C}$ before trimming.

Table 1. Resin cements chemical composition.

\begin{tabular}{|c|c|}
\hline Resin cement type & Chemical composition \\
\hline \multirow{2}{*}{ Type 1} & Organic matrix: BisGMA and TEGDMA (1:1 mass ratio). \\
\hline & $\operatorname{EDMAB}(0.8 w+\%), \mathrm{CQ}(0.2 \mathrm{w}+\%), \mathrm{BHT}(0.1 \mathrm{wt} \%)$ and barium borosilicate glass filler ( $1: 1$ mass ratio with the resin matrix) \\
\hline \multirow{2}{*}{ Type 2} & Organic matrix: BisGMA, TEGDMA and UDMA (5:2:3 mass ratio). \\
\hline & $\operatorname{EDMAB}(0.8 \mathrm{w}+\%), \mathrm{CQ}(0.2 \mathrm{w}+\%), \mathrm{BHT}(0.1 \mathrm{wt} \%)$ and barium borosilicate glass filler ( $1: 1$ mass ratio with the resin matrix) \\
\hline
\end{tabular}

BisGMA bis-phenol A dyglycidyl dimethacrylate, TEGDMA tri-ethylene glycol dimethacrylate, UDMA urethane dimethacrylate, EDMAB ethyl 4-dimethylaminobenzoate, $C Q$ dl-camphoroquinone, $\mathrm{BHT}$ 2,6-di-tert-butyl-4-methylphenol 
Microtensile bond strength ( $\mu$ TBS) evaluation

Cuts perpendicular to the bonded interface were made using a water-cooled diamond blade (Dia. Wafer Blade, Esstech Corp., Enfiled, USA) in the ' $X$ ' and ' $Y$ ' directions using a precision sectioning machine (Accutom-5, Struers, Cleveland, USA) to obtain $1 \mathrm{~mm}^{2}$ EMX/dentin sticks. Each stick was fixed to the grips of a $\mu$ TBS device using a cyanoacrylate adhesive (Zap CA superglue, Ontario, Canada) and the $\mu$ TBS was determined using a universal testing machine (MTS Criterion, Model 42, Eden Prairie, USA) at $0.5 \mathrm{~mm} / \mathrm{min}$ crosshead speed until failure. Half of the obtained EMX/dentin sticks were stored in deionized water for 24 hours before the $\mu \mathrm{TBS}$, while the other half were stored in deionized water for 6 months for further bond strength evaluation (water was replaced every 15 days).

\section{Failure analysis}

The fractured specimens were observed using an optical microscopy at $30 \times$ and $100 \times$ magnifications and failure modes were classified as: adhesive, cohesive within ceramic, cohesive within dentin, and mixed, which involved ceramic, resin cement, adhesive interface and dentin. A representative sample from each failure mode was subjected to FE-SEM analysis. The fractured specimens were prepared as described in the topic "Field-emission scanning electron microscopy (FE-SEM) evaluation".

\section{Statistical analysis}

The experimental unit considered for $\mu \mathrm{TBS}$ test was the EMX/dentin blocks. The data of $\mu$ TBS at immediate (24 hours) and after 6-month water-storage were submitted to split-plot three-way analysis of variance (hydrofluoric acid concentration $\times$ resin cement formulation $\times$ storage time) and multiple comparisons were performed using the Tukey's post hoc test $(\alpha=0.05)$.

\section{Results}

\section{IPS e.max press etching pattern}

The etching patterns of IPS e.max Press are represented in Figure 1. The HF concentrations of $1 \%$ and $5 \%$ (Figures $1 \mathrm{~A}$ and $1 \mathrm{~B}$, respectively) resulted in
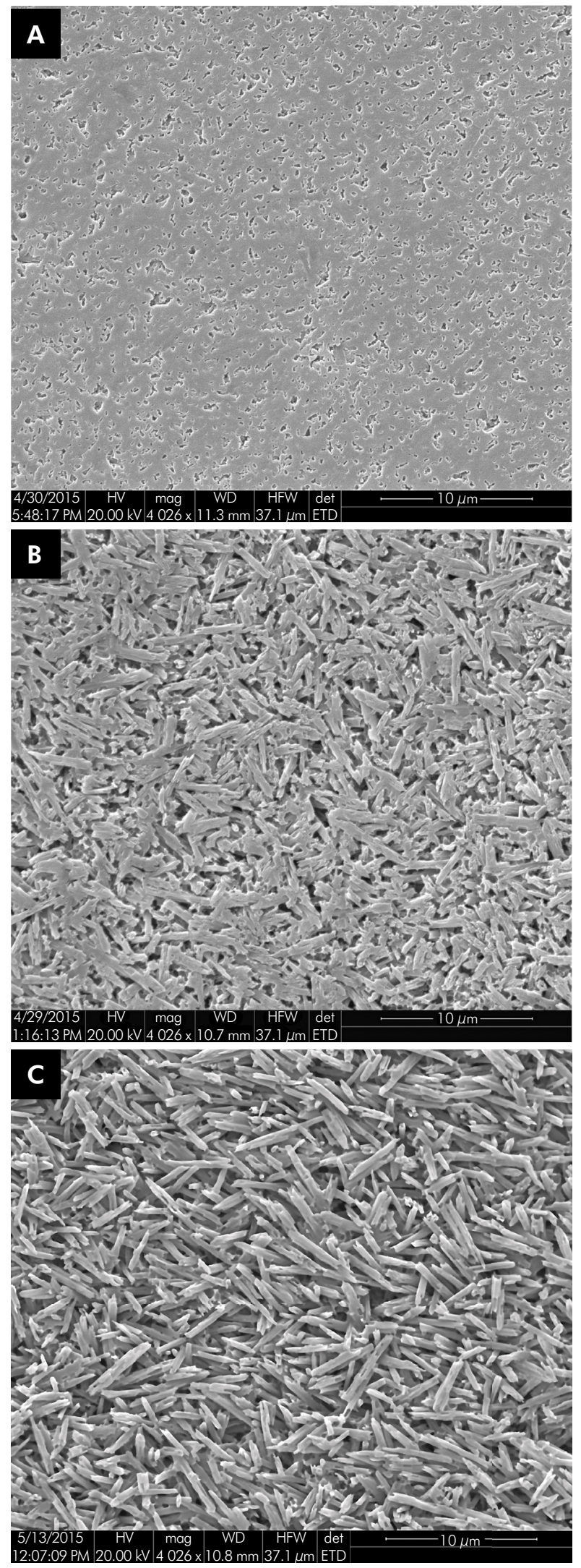

Figure 1. Resulted etching pattern on IPS e.max Press with $1 \%$ (A), 5\% (B) and 10\% (C) hydrofluoric acid applied for 20 seconds. 
a superficial etching pattern when compared to $10 \%$, as they removed a lower amount of vitreous phase associated with less lithium disilicate crystal exposure. The highest HF concentration (10\%, Figure 1C) showed the greatest removal of vitreous phase and exposure of the lithium disilicate crystals.

\section{Microtensile bond strength ( $\mu \mathrm{TBS}$ )}

The mean $\mu$ TBS values are shown in Table 2 . HF concentration $\times$ resin cement matrix $(p=0.1107)$, HF concentration $\times$ storage time $(\mathrm{p}=0.5375)$, resin cement matrix $\times$ storage time $(p=0.7587)$ and the triple interaction ' $\mathrm{HF}$ concentration $\times$ resin cement matrix $\times$ storage time' $(p=0.1877)$ did not show significant interactions between factors. Significant differences for resin cement matrix $(p=0.0312)$, HF concentration $(p=0.014)$ and storage time $(p=0.0002)$ were detected.

The different HF concentrations affected the $\mu \mathrm{TBS}$ values for resin cement type 1 (Table 2), with 10\% HF showing a statistically higher $\mu$ TBS value when compared to $1 \%$ at both storage times; whilst the HF concentrations revealed statistically similar $\mu$ TBS values for resin cement type 2 at both storage times (Table 2). Both resin cement formulations showed decreased $\mu$ TBS values after 6 months of water storage, except for $10 \%$ HF associated with resin cement type 1, which water storage did not decrease the $\mu \mathrm{TBS}$ value.

\section{Failure modes analysis}

A descriptive analysis of failure modes is shown in Table 3 . At the 24 hour-storage time, a predominance of

Table 2. Mean microtensile bond strength values $(\mathrm{MPa}) \pm$ standard deviation of type 1 and 2 resin cements. Within each resin cement type, means followed by different letters (uppercase letters in line and lowercase letters in column) indicate significant statistical differences according to Tukey`s test $(p<0.05)$.

\begin{tabular}{lccc}
\hline \multirow{2}{*}{ Resin cement matrix } & Hydrofluoric acid concentration & \multicolumn{2}{c}{ Storage time } \\
\cline { 3 - 4 } & & $24 \mathrm{~h}$ & 6 -month \\
BisGMA + TEGDMA (type 1) & $5 \%$ & $22.2( \pm 5.7) \mathrm{Ab}$ & $19.6( \pm 6.5) \mathrm{Bb}$ \\
& $10 \%$ & $23.7( \pm 2.9) \mathrm{Aab}$ & $19.8( \pm 3.9) \mathrm{Bab}$ \\
BisGMA + TEGDMA + UDMA (type 2) & $1 \%$ & $26.7( \pm 2.9) \mathrm{Aa}$ & $26.2( \pm 5.5) \mathrm{Aa}$ \\
& $5 \%$ & $22.6( \pm 2.1) \mathrm{Aa}$ & $19.8( \pm 4) \mathrm{Ba}$ \\
\end{tabular}

Table 3. Failure Modes Analysis (total number followed by \% in parentheses) of the debonded specimens among groups.

\begin{tabular}{|c|c|c|c|c|}
\hline \multirow{2}{*}{ Groups } & \multicolumn{4}{|c|}{ Failure Modes } \\
\hline & Adhesive & Cohesive within ceramic & Cohesive within dentin & Mixed \\
\hline \multicolumn{5}{|l|}{ Storage time $24 \mathrm{~h}$} \\
\hline $1 \% \mathrm{HF}+$ Bis-GMA/TEGDMA & $30(43)$ & $12(17)$ & $1(2)$ & $22(38)$ \\
\hline $1 \% \mathrm{HF}+$ Bis-GMA/TEGDMA/UDMA & $29(44)$ & $15(23)$ & $3(4)$ & 19 (29) \\
\hline $5 \% \mathrm{HF}+$ Bis-GMA/TEGDMA & $16(27)$ & $10(17)$ & $15(26)$ & $17(30)$ \\
\hline $5 \% \mathrm{HF}+$ Bis-GMA/TEGDMA/UDMA & $6(10)$ & $19(31)$ & $11(17)$ & $27(42)$ \\
\hline $10 \% \mathrm{HF}+$ Bis-GMA/TEGDMA & $29(45)$ & $18(28)$ & $-\cdots--$ & $18(27)$ \\
\hline $10 \% \mathrm{HF}+$ Bis-GMA/TEGDMA/UDMA & $29(47)$ & $16(25)$ & $3(5)$ & $14(23)$ \\
\hline \multicolumn{5}{|l|}{ Storage time 6-month } \\
\hline $1 \% \mathrm{HF}+$ Bis-GMA/TEGDMA & $24(35)$ & $11(16)$ & $2(3)$ & $32(46)$ \\
\hline $1 \% \mathrm{HF}+$ Bis-GMA/TEGDMA/UDMA & $19(27)$ & $13(19)$ & $2(3)$ & $35(51)$ \\
\hline $5 \% \mathrm{HF}+$ Bis-GMA/TEGDMA & $26(42)$ & $8(13)$ & $3(5)$ & $25(40)$ \\
\hline $5 \% \mathrm{HF}+$ Bis-GMA/TEGDMA/UDMA & $13(20)$ & $3(5)$ & ----- & $47(75)$ \\
\hline $10 \% \mathrm{HF}+$ Bis-GMA/TEGDMA & $17(26)$ & $12(19)$ & $3(4)$ & $33(51)$ \\
\hline $10 \% \mathrm{HF}+$ Bis-GMA/TEGDMA/UDMA & $5(9)$ & $15(28)$ & $1(2)$ & $33(61)$ \\
\hline
\end{tabular}


adhesive, cohesive within ceramic and mixed failures was verified. At the 6-month storage time, there was a prevalence of mixed failures for all tested groups and a decrease in the cohesive failures in dentin for the groups etched with 5\% HF. Figure 2 shows the representative FE-SEM images of each failure mode obtained.

\section{Discussion}

The HF etching mechanism on lithium disilicate glass-ceramic basically consists of removing the glassy matrix due to the greater affinity of fluoride (present in the HF acid) reacting with silicon when compared to oxygen, which enables the ionized HF to dissolve the silicon-oxygen bonds (silanol) present in the glass ceramic. ${ }^{9}$ Consequently, there is an exposure of lithium disilicate crystals that will be future sites for micromechanical interlocking for resin cements. ${ }^{10,11,12}$ The FE-SEM images (Figure 1) depicted a superficial etching pattern for $1 \% \mathrm{HF}$ and considerable removal of the glassy matrix and exposure of lithium disilicate crystals for $10 \% \mathrm{HF}$,
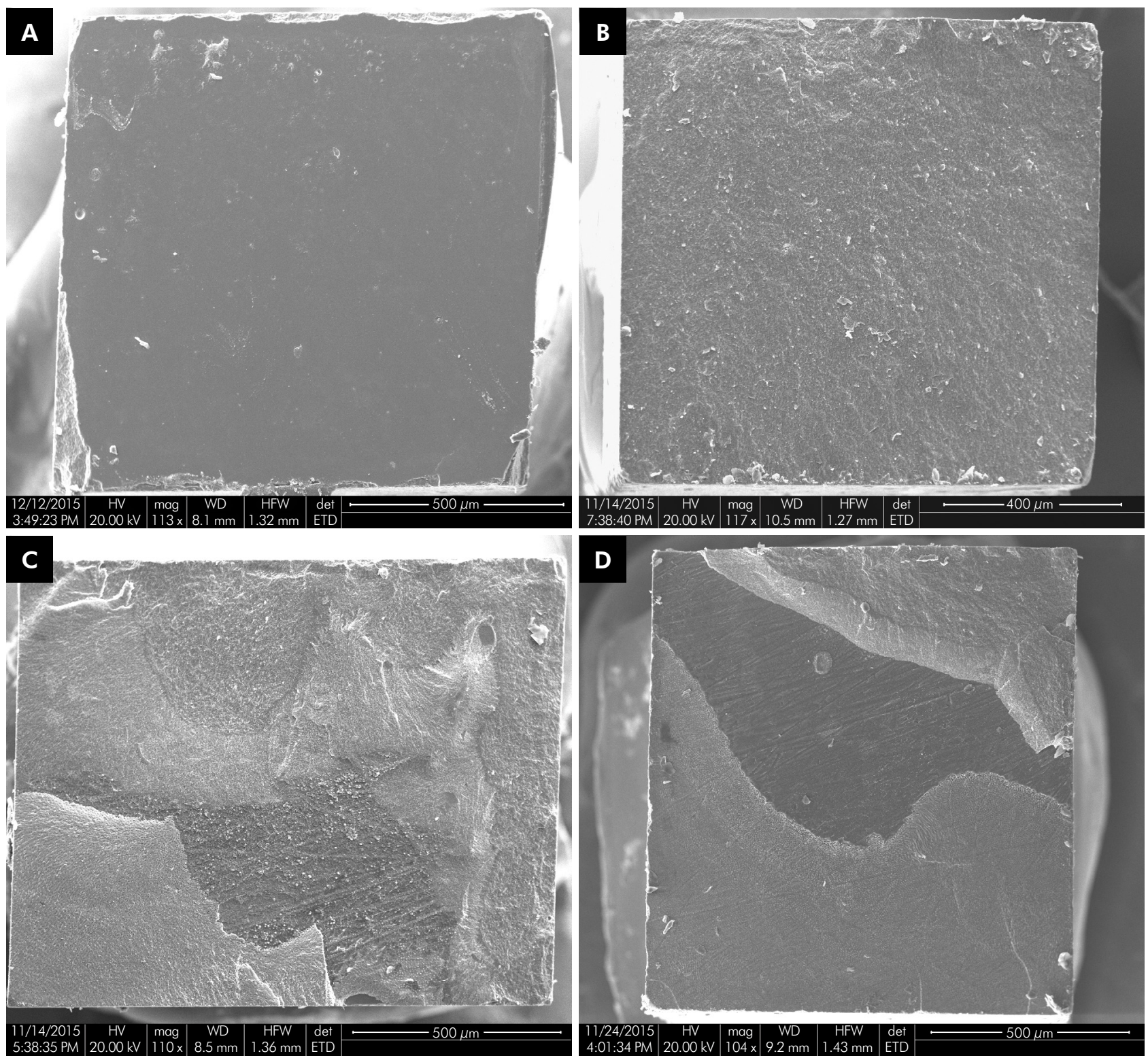

Figure 2. Representative FE-SEM of fractured EMX-dentin sticks. A) Adhesive failure; B) Cohesive failure within ceramic; C) Cohesive failure within dentin; D) mixed failure involving ceramic, adhesive interface and dentin. 
while $5 \%$ HF performed in between the $1 \%$ and $10 \%$ HF. The reason for this is that low HF concentrations present lower amounts of ionized HF to react with the glassy matrix, ${ }^{10,11,12}$ producing a more superficial etching pattern (Figure 1A). Previous in vitro studies have also verified increased removal of the glassy matrix with higher HF concentrations. ${ }^{10,11,12,26}$

The increased removal of the glassy matrix achieved with higher HF concentrations applied to lithium disilicate ceramics is directly related with higher bond strength values. . $11,12^{1,1}$ However, in the present study, the different HF concentrations only affected the $\mu \mathrm{TBS}$ for the groups luted with resin cement type 1 (BisGMA/TEGDMA), a condition that was not confirmed for resin cement type 2 (BisGMA/TEGDMA/UDMA), with the three HF concentrations $(1 \%, 5 \%$ and $10 \%)$ demonstrating statistically similar $\mu \mathrm{TBS}$ values. This partially denies our first and second hypothesis. It may be noted that the increased viscosity of the resin cement containing UDMA (BisGMA- molecular weight: $510.6 \mathrm{~g} / \mathrm{mol}$, viscosity: 1200 Pa s; TEGDMA- molecular weight: $286.3 \mathrm{~g} / \mathrm{mol}$, viscosity: 0.01 Pa s; UDMA- molecular weight: $470 \mathrm{~g} / \mathrm{mol}$, viscosity: $23.1 \mathrm{~Pa} \mathrm{~s})^{24}$ hindered the micromechanical interlocking to the etched surface of the lithium disilicate ceramic, thus decreasing/ limiting the effect of EMX etching pattern on the bond strength values. On the other hand, a less viscous resin cement (better flowability), such as resin cement type 1 , can better infiltrate/interact with the etched EMX surface irregularities, explaining the greater influence of $\mathrm{HF}$ on the $\mu \mathrm{TBS}$ results (such as $10 \% \mathrm{HF}$, Fig. 1C). Additionally, UDMA not only favors crosslinking ${ }^{27}$ but also promotes higher flexural strength, elastic modulus and hardness ${ }^{28}$ of composite materials. Even though the cement materials are definitely not composites, they share a lot of commonalities in composition. In fact, the main difference is often only in the filler content. All those combined factors may have led to increased mechanical properties of the resin cement containing UDMA ${ }^{24,29}$ and counteracted the lower micromechanical interlocking to etched EMX with lower HF concentrations. Therefore, it may be speculated that the decreased mechanical entanglement of more viscous resin cements into the surface irregularities on EMX is somehow compensated for by the mechanical properties of the resin cement matrix and by the chemical bonding via a silane coupling agent.

Most of the evaluated groups showed decreased $\mu$ TBS values after water storage, negating our third hypothesis. BisGMA, TEGDMA and UDMA are susceptible to hydrolytic cleavage due the presence of polar groups within their chemical compositions that binds, via hydrogen bonds, to water and plasticizes the polymer (hydroxyl groups $(-\mathrm{OH}) \rightarrow$ BisGMA; urethane linkages $(-\mathrm{NH}=) \rightarrow$ UDMA and ether linkages (-O-) $\rightarrow$ TEGDMA).22,30 As water diffuses through the nanometer-sized pores within polymers, more plasticization and degradation can take place (reduction in mechanical properties), ${ }^{22,30}$ jeopardizing the bond strength stability over time. Along with the resin matrix plasticization, water molecules tend to degrade the siloxane bonds (bond between silanol groups of silica surface and the silane coupling agent at the filler) via a hydrolysis reaction, causing filler debonding ${ }^{31}$ and decreasing the mechanical properties of resin cements. Venz and Dickens ${ }^{25}$ demonstrated that the hydrophilicity of monomers follows the descending order: TEGDMA > BisGMA > UDMA. Therefore, water uptake by BisGMA-based resins increases in direct proportion to the concentration of TEGDMA and decreases with the partial substitution of TEGDMA by UDMA. ${ }^{32}$ Thus, it might be expected that resin cements with a higher TEGDMA content will present lower physical properties over time, promoting a greater negative influence on bond stability. Nevertheless, an improved and greater resin cement micromechanical interlocking into a more conditioned EMX surface (greater glassy matrix removal and exposure of lithium disilicate crystals) may have countered the resin matrix water degradation, as was seen in the group treated with $10 \% \mathrm{HF}$ associated with resin cement type 1 , at least up to 6 months of water storage.

Along with resin cement matrix plasticization, the dentin-adhesive interfaces are also susceptible to degradation. Two main mechanisms synergistically affect the bond stability to dentin: 1) the collagenolytic activity of host-derived dentin metalloproteinase at exposed collagen fibrils not infiltrated by adhesive resin; and, 2) adhesive polymer plasticization. ${ }^{33,34,35}$ Although 
the 3-step etch-and-rinse adhesive system (Scotchbond MultiPurpose) is recognized as the gold standard in terms of bonding stability over time, ${ }^{36}$ Anchieta et al. ${ }^{37}$ found decreased mechanical properties (elastic modulus) of the dentin-hybrid layer when Scotchbond MultiPurpose was evaluated after water storage. Additionally, the hybrid layer is mainly formed by a low molecular weight monomer (HEMA), which presents hydrophilic characteristics and lower mechanical properties. ${ }^{38,39}$ All those combined factors play an important role on dentin-adhesive interface degradation, causing lower bond strength values after water aging.

The failure modes from the $\mu$ TBS analysis showed similar incidences for adhesive, cohesive within ceramic, and mixed failures at the 24-hour period. However, the incidence of mixed failures increased after aging, which may be linked to polymer degradation. Adhesive failure does not always indicate poor bonding, but that the interfacial bond strength has been truly evaluated.$^{40}$ However, flaws within the dentin or ceramic (cracks or bubbles) and the association of non-uniform stress distribution during either bond strength testing or the trimming procedures to obtain sticks for $\mu \mathrm{TBS}$ analysis may have triggered the cohesive failures during tension.

It is valuable to note the $\mu \mathrm{TBS}$ results found for the association of $\mathrm{HF}$ concentrations and resin cement type 2 (BisGMA/TEGDMA/UDMA). Despite the decreased $\mu$ TBS after water storage, it is possible to etch the EMX surface prior to luting using $1 \% \mathrm{HF}$ acid as this group showed similar bond strength performance to $5 \%$ and $10 \% \mathrm{HF}$ at both storage times. This is an interesting outcome considering the hazardous nature of HF because applying low HF concentrations would directly benefit dentists, dental personal, patients and prosthetic technicians. However, clinical studies are necessary to confirm the present study. Also, the

\section{References}

\footnotetext{
1. Höland W, Schweiger M, Frank M, Rheinberger V. A comparison of the microstructure and properties of the IPS Empress 2 and the IPS Empress glass-ceramics. J Biomed Mater Res. 2000;53(4):297-303. https://doi.org/10.1002/10974636(2000)53:4<297::AID-JBM3>3.0.CO;2-G
}

present bond strength results contrasts with previous in vitro studies, ${ }^{10,11}$ which reported lower bond strength results for $1 \% \mathrm{HF}$ when compared to $5 \%$ and $10 \% \mathrm{HF}$, but those studies focused on the resin cement-lithium disilicate ceramic interface.

One important observation obtained from the present in vitro study is that the bond strength between lithium disilicate glass-ceramic to dentin involves the synergic role between two distinct interfaces: glass ceramic-resin cement and resin cement-dentin. According to previous studies, ${ }^{6,26}$ the glass ceramicresin cement interface appears to be more hydrolithicly stable than the resin materials-dentin interface. ${ }^{37}$ These results recognize that the interface of resin materials to dentin is the weak link for the bond strength durability of glass ceramics to dentin. Therefore, dentists must execute state-of-the-art bonding using high quality dental materials in order to contribute to the survival rate of glass ceramic restorations.

\section{Conclusion}

If resin cement type 1 formulation is considered for luting glass-ceramics to dentin, $10 \% \mathrm{HF}$ should be preferred, as it yielded higher and more stable bond strength values after water aging. On the contrary, as the bond strength results demonstrated that the resin cement containing UDMA (type 2) was not affected by different HF concentrations, 1\% HF may be indicated over $5 \%$ and $10 \%$, considering the hazardous nature of HF.

\section{Acknowledgments}

This work was supported by Fapesp [São PauloState Research Foundation, grant numbers 2013/26573-7 and 2014/23320-3] and NIH/NIDCR [1R15 DE023211 $01 \mathrm{~A} 1$ and U01 DE02756 02].

\footnotetext{
2. Collares K, Corrêa MB, Laske M, Kramer E, Reiss B, Moraes RR et al. A practice-based research network on the survival of ceramic inlay/onlay restorations. Dent Mater. 2016 May;32(5):687-94. https://doi.org/10.1016/i.dental.2016.02.006
} 
3. Shibata S, Taguchi C, Gondo R, Stolf SC, Baratieri LN. Ceramic Veneers and Direct-Composite Cases of Amelogenesis Imperfecta Rehabilitation. Oper Dent. 2016 May-Jun;41(3):233-42. https://doi.org/10.2341/15-079-TP

4. Xiaoping L, Dongfeng R, Silikas N. Effect of etching time and resin bond on the flexural strength of IPS e.max Press glass ceramic. Dent Mater. 2014 Dec;30(12):e330-6. https://doi.org/10.1016/i.dental.2014.08.373

5. Tian T, Tsoi JK, Matinlinna JP, Burrow MF. Aspects of bonding between resin luting cements and glass ceramic materials. Dent Mater. 2014 Jul;30(7):e147-62. https://doi.org/10.1016/j.dental.2014.01.017

6. Makishi P, André CB, Silva JL, Bacelar-Sá R, CorrerSobrinho L, Giannini M. Effect of Storage Time on Bond Strength Performance of Multimode Adhesives to Indirect Resin Composite and Lithium Disilicate Glass Ceramic. Oper Dent. 2016 Sep-Oct;41(5):541-51. https://doi.org/10.2341/15-187-L

7. Lise DP, Perdigão J, Van Ende A, Zidan O, Lopes GC. Microshear Bond Strength of Resin Cements to Lithium Disilicate Substrates as a Function of Surface Preparation. Oper Dent. 2015 Sep-Oct;40(5):524-32. https://doi.org/10.2341/14-240-L

8. Öztürk E, Bolay \$, Hickel R, llie N. Shear bond strength of porcelain laminate veneers to enamel, dentine and enamel-dentine complex bonded with different adhesive luting systems. J Dent. 2013 Feb;41(2):97-105. https://doi.org/10.1016/j.jdent.2012.04.005

9. Ozcan M, Allahbeickaraghi A, Dündar M. Possible hazardous effects of hydrofluoric acid and recommendations for treatment approach: a review. Clin Oral Investig. 2012 Feb;16(1):15-23. https://doi.org/10.1007/s00784-011-0636-6

10. Sundfeld D, Correr-Sobrinho L, Pini NI, Costa AR, Sundfeld RH, Pfeifer CS et al. Heat treatment-improved bond strength of resin cement to lithium disilicate dental glass-ceramic. Ceram Int. 2016;42(8):10071-8. https://doi.org/10.1016/i.ceramint.2016.03.112.

11. Sundfeld Neto D, Naves LZ, Costa AR, Correr AB, Consani S, Borges GA et al. The effect of hydrofluoric acid concentration on the bond strength and morphology of the surface and interface of glass ceramics to a resin cement. Oper Dent. 2015 Sep-Oct;40(5):470-9. https://doi.org/10.2341/14-133-L PMID:25764043

12. Sundfeld D, Correr-Sobrinho L, Pini NI, Costa AR, Sundfeld RH, Pfeifer CS et al. The Effect of Hydrofluoric Acid Concentration and Heat on the Bonding to Lithium Disilicate Glass Ceramic. Braz Dent J. 2016 Oct-Dec;27(6):727-33. https://doi.org/10.1590/01036440201601024PMID:27982186

13. Klosa K, Boesch I, Kern M. Long-term bond of glass ceramic and resin cement: evaluation of titanium tetrafluoride as an alternative etching agent for lithium disilicate ceramics. J Adhes Dent. 2013 Aug;15(4):377-83. https://doi.org/10.3290/i.jad.a29381 PMID:23534032
14. Panah FG, Rezai SM, Ahmadian L. The influence of ceramic surface treatments on the microshear bond strength of composite resin to IPS Empress 2. J Prosthodont. 2008 Jul;17(5):409-14. https://doi.org/10.1111/j.1532-849X.2007.00296.x

15. Pisani-Proença J, Erhardt MC, Valandro LF, GutierrezAceves G, Bolanos-Carmona MV, Del Castillo-Salmeron $R$ et al. Influence of ceramic surface conditioning and resin cements on microtensile bond strength to a glass ceramic. J Prosthet Dent. 2006;96(6):412-7. https://doi.org/10.1016/i.prosdent.2006.09.023

16. Manso AP, Silva NR, Bonfante EA, Pegoraro TA, Dias RA, Carvalho RM. Cements and adhesives for all-ceramic restorations. Dent Clin North Am. 2011 Apr;55(2):311-32. https://doi.org/10.1016/i.cden.2011.01.011

17. Rosenstiel SF, Land MF, Crispin BJ. Dental luting agents: A review of the current literature. J Prosthet Dent. 1998 Sep;80(3):280-301. https://doi.org/10.1016/S0022-3913(98)70128-3

18. Rigolin FJ, Miranda ME, Flório FM, Basting RT. Evaluation of bond strength between leucite-based and lithium disilicatebased ceramics to dentin after cementation with conventional and self-adhesive resin agents. Acta Odontol Latinoam. 2014;27(1):16-24.

19. Marocho SM, Ozcan M, Amaral R, Bottino MA, Valandro LF. Effect of resin cement type on the microtensile bond strength to lithium disilicate ceramic and dentin using different test assemblies. J Adhes Dent. 2013 Aug;15(4):361-8. https://doi.org/10.3290/i.jad.a28624

20. Bitter K, Paris S, Hartwig C, Neumann K, Kielbassa AM. Shear bond strengths of different substrates bonded to lithium disilicate ceramics. Dent Mater J. 2006 Sep;25(3):493-502. https://doi.org/10.4012/dmi.25.493

21. Walters NJ, Xia W, Salih V, Ashley PF, Young AM. Poly(propylene glycol) and urethane dimethacrylates improve conversion of dental composites and reveal complexity of cytocompatibility testing. Dent Mater. 2016 Feb;32(2):264-77. https://doi.org/10.1016/i.dental.2015.11.017

22. Ferracane JL. Hygroscopic and hydrolytic effects in dental polymer networks. Dent Mater. 2006 Mar;22(3):211-22. https://doi.org/10.1016/i.dental.2005.05.005

23. Gajewski VE, Pfeifer CS, Fróes-Salgado NR, Boaro LC, Braga RR. Monomers used in resin composites: degree of conversion, mechanical properties and water sorption/solubility. Braz Dent J. 2012;23(5):508-14. https://doi.org/10.1590/S0103-64402012000500007

24. Barszczewska-Rybarek IM. Structure-property relationships in dimethacrylate networks based on Bis-GMA, UDMA and TEGDMA. Dent Mater. 2009 Sep;25(9):1082-9. https://doi.org/10.1016/i.dental.2009.01.106

25. Venz S, Dickens B. NIR-spectroscopic investigation of water sorption characteristics of dental resins and composites. J Biomed Mater Res. 1991 Oct;25(10):1231-48. https://doi.org/10.1002/jbm.820251005 
The effect of hydrofluoric acid and resin cement formulation on the bond strength to lithium disilicate ceramic

26. Venturini AB, Prochnow C, Rambo D, Gundel A, Valandro LF. Effect of hydrofluoric acid concentration on resin adhesion to a feldspathic ceramic. J Adhes Dent. 2015 Aug;17(4):313-20. https://doi.org/10.3290/i.jad.a34592

27. Pick B, Pelka M, Belli R, Braga RR, Lohbaver U. Tailoring of physical properties in highly filled experimental nanohybrid resin composites. Dent Mater. 2011 Jul;27(7):664-9. https://doi.org/10.1016/j.dental.2011.03.007PMID:21514956

28. Tanimoto Y, Hayakawa T, Nemoto K. Analysis of photopolymerization behavior of UDMA/TEGDMA resin mixture and its composite by differential scanning calorimetry. J Biomed Mater Res B Appl Biomater. 2005 Feb;72(2):310-5. https://doi.org/10.1002/jbm.b.30151PMID:15449252

29. Floyd CJ, Dickens SH. Network structure of Bis-GMA- and UDMA-based resin systems. Dent Mater. 2006 Dec;22(12):11439. https://doi.org/10.1016/i.dental.2005.10.009

30. Reis A, Martins GC, de Paula EA, Sanchez AD, Loguercio $A D$. Alternative aging solutions to accelerate resin-dentin bond degradation. J Adhes Dent. 2015 Aug;17(4):321-8. https://doi.org/10.3290/i.jad.a34591

31. Curtis AR, Shortall AC, Marquis PM, Palin WM. Water uptake and strength characteristics of a nanofilled resinbased composite. J Dent. 2008 Mar;36(3):186-93. https://doi.org/10.1016/i.jdent.2007.11.015

32. Turgut $S$, Bagis B. Colour stability of laminate veneers: an in vitro study. J Dent. 2011 Dec;39(3 Suppl 3):e57-64. https://doi.org/10.1016/i.jdent.2011.11.006

33. Mazzoni A, Scaffa P, Carrilho M, Tiäderhane L, Di Lenarda R, Polimeni $A$ et al. Effects of etch-and-rinse and self-etch adhesives on dentin MMP-2 and MMP-9. J Dent Res. 2013 Jan;92(1):82-6. https://doi.org/10.1177/0022034512467034
34. Pashley DH, Tay FR, Breschi L, Tiäderhane L, Carvalho RM, Carrilho M et al. State of the art etch-andrinse adhesives. Dent Mater. 2011 Jan;27(1):1-16. https://doi.org/10.1016/i.dental.2010.10.016

35. Pashley DH, Tay FR, Yiu C, Hashimoto M, Breschi L, Carvalho RM et al. Collagen degradation by host-derived enzymes during aging. J Dent Res. 2004 Mar;83(3):216-21. https://doi.org/10.1177/154405910408300306

36. Sadek FT, Castellan CS, Braga RR, Mai S, Tiäderhane $\mathrm{L}$, Pashley DH et al. One-year stability of resin-dentin bonds created with a hydrophobic ethanol-wet bonding technique. Dent Mater. 2010 Apr;26(4):380-6. https://doi.org/10.1016/i.dental.2009.12.009

37. Anchieta RB, Machado LS, Martini AP, Santos PH, Giannini M, Janal M et al. Effect of long-term storage on nanomechanical and morphological properties of dentinadhesive interfaces. Dent Mater. 2015 Feb;31(2):141-53. https://doi.org/10.1016/i.dental.2014.11.010

38. Tay FR, Pashley DH. Aggressiveness of contemporary self-etching systems. I: depth of penetration beyond dentin smear layers. Dent Mater. 2001 Jul;17(4):296-308. https://doi.org/10.1016/S0109-5641(00)00087-7

39. Van Landuyt KL, Snauwaert J, De Munck J, Peumans $M$, Yoshida Y, Poitevin A et al. Systematic review of the chemical composition of contemporary dental adhesives. Biomaterials. 2007 Sep;28(26):3757-85. https://doi.org/10.1016/j.biomaterials.2007.04.044

40. Della Bona A, Anusavice KJ, Mecholsky JJ Jr. Failure analysis of resin composite bonded to ceramic. Dent Mater. 2003 Dec;19(8):693-9. https://doi.org/10.1016/S0109-5641(03)00015-0 